\title{
Metformin delivery using chitosan-capped gold nanoparticles in glioblastoma cell lines
}

\author{
Mihaela Aldea ${ }^{1}$, Ioan Stefan Florian ${ }^{2}$, Monica Potara ${ }^{3}$, \\ Olga Soritau ${ }^{4}$, Timea Nagy-Simon ${ }^{3}$, Gabriel Kacso ${ }^{1,5}$
}

\author{
${ }^{1}$ Department of Medical Oncology and Radiotherapy, Iuliu Hatieganu University of Medicine and \\ Pharmacy, Cluj-Napoca, ROMANIA \\ ${ }^{2}$ Department of Neurosurgery, Iuliu Hatieganu University of Medicine and Pharmacy, Cluj- \\ Napoca, ROMANIA \\ ${ }^{3}$ Nanobiophotonics and Laser Microscopy Center, Interdisciplinary Research in Bio-Nano- \\ Sciences, and Faculty of Physics, Babes-Bolyai University, Cluj-Napoca, ROMANIA \\ ${ }^{4}$ Department of Tumor Biology, Ion Chiricuta Cancer Institute, Cluj-Napoca, ROMANIA \\ ${ }^{5}$ Amethyst Radiotherapy Center, Cluj, ROMANIA
}

\begin{abstract}
Introduction: Metformin (MET), an old anti-diabetic drug, has proven unexpected anti-glioblastoma effects, by impacting cell proliferation, migration and invasion. However, its remarkable anti-cancer efficacy is mainly limited to the use of high millimolar concentrations in in vitro studies, which are hard to be attained in the clinical setting. Aim: The aim of this paper was to synthetize gold nanoparticles loaded with MET and to test if an enhanced drug delivery via nanotechnology could overcome the limitations of small drug concentrations. Materials and Methods: Gold nanoparticles were functionalized with chitosan (GNPc) and loaded with $80 \mu \mathrm{M}$ of MET. Their size, zeta potential and stability were characterized and their internalization within tumor cells was assayed through dark field microscopy. Three primary glioblastoma stem cell lines were treated with 5,10 and $20 \mu \mathrm{g} / \mathrm{mL}$ concentrations of nanoparticles and irradiated. The anti-tumoral effect was evaluated through the MTT cell viability assay. Results: MET-GNPc are easily synthetized and have a positive zeta potential, spherical shape and a median size of $26 \mathrm{~nm}$. MET-GNPc have an increased cell internalization and affect the viability of all three glioblastoma cell lines used compared to control and free MET. However, their anti-cancer effect is not statistically different when compared to GNPc, although a slight tendency to a better response may be observed. Conclusion:Despite an increased cell internalization, the small micromolar concentrations of metformin does not bring an additional benefit to chitosan-based GNPs. Novel delivery methods being able to carry a higher drug concentration of metformin should be tested.
\end{abstract}




\section{Introduction}

Metformin (MET), a well-known oral antidiabetic, has been regarded as an extremely promising anticancer agent in many cancer types. In vitro and in vivo experiments proved a myriad of mechanisms of action, including decreased cell proliferation, cell cycle arrest, autophagy, apoptosis and cell death in vitro with a concomitant activation of AMPK and inhibition of the mTOR pathway, while also sensitizing cells to radiotherapy (M. Aldea et al., 2014; M. D. Aldea et al., 2014; Carmignani et al., 2014; Nenu et al., 2014; Sesen et al., 2015; Soritau et al., 2011). Our team investigated MET in glioblastoma cell lines and proved a surprising reduction of glioblastoma stem-like cells proliferation (M. D. Aldea et al., 2014; Carmignani et al., 2014; Soritau et al., 2011).

However, this benefits were observed mainly at supra-clinical doses of 1-10 mM, which are easily obtained in vitro or in vivo experiments, but are unlikely to be obtained in the clinical setting (M. Aldea et al., 2014). Clinical cancer trials that have tested MET with the same doses used in anti-diabetic therapy failed to translate into a relevant tumor response, possibly due to lack of MET adequate high concentrations for cancer cell killing (Kordes et al., 2015; Reni et al., 2016; Sayed, Saad, El Wakeel, Elkholy, \& Badary, 2015).

We hypothesize that MET tumor targeted delivery by nanotechnology might overcome the ineffectiveness of small drug concentrations. Therefore, in this study, we synthetized gold nanoparticles loaded with micromolar concentrations of MET in order to test if such low dose compounds reach the anticancer effects observed with high free drug MET therapy.

\section{Materials and Methods}

\section{Nanoparticles preparation and metformin loading}

Citrate-capped gold nanoparticles (GNPc) were synthetized following the Turkevich-Frens method and by slightly modifying the method used in our previous experiments (Aldea M, 2018; Potara, Maniu, \& Astilean, 2009; Turkevich J, 1951). Briefly, 100 $\mathrm{mL}$ of hydrogen tetrachloroaurate(III) trihydrate $\mathrm{HAuCl} 4 \cdot 3 \mathrm{H} 2 \mathrm{O}(10-3 \mathrm{M})$ were heated to a boiling temperature and then mixed to trisodium citrate $(10 \mathrm{~mL}, 38.8 \times 10-3$ M) (Merck) under vigorous stirring. After the formation of a deep-red burgundy colloid, the stirring and boiling processed were continued for 10-15 min. Subsequently, the heating was stopped and the stirring process was continued for another $15 \mathrm{~min}$. Then, $3 \mathrm{ml}$ of 10-3 M HAuCl4 were mixed with $18 \mathrm{ml}$ of 2 $\mathrm{mg} / \mathrm{mL}$ chitosan solution (medium molecular weight), and then heated to $50{ }^{\circ} \mathrm{C}$. The colloidal solutions were centrifugated and resuspended in ultrapure water. Loading of metformin hydrochloride (MET) (Sigma Aldrich) onto the surface of GNPc was performed by incubating the colloidal GNPc with MET at $\mathrm{pH}$ 3.5. The $\mathrm{pH}$ of the mixture was then adjusted to 8 with $1 \mathrm{M} \mathrm{NaOH}$. The obtained metformin gold nanoconjugates (MET-GNPc) were subsequently washed to 
remove the free drug. All materials were purchased from Sigma Aldrich, unless otherwise specified.

\section{Structural characterization of NPs - zeta potential, gold concentration, size}

Optical extinction spectra of NPs were collected in a $2 \mathrm{~mm}$ quartz cell using a Jasco V670 spectrophotometer with $1 \mathrm{~nm}$ spectral resolution. The zeta potential was recorded at $25^{\circ} \mathrm{C}$ using a Malvern Zetasizer Nano ZS-90 instrument. The concentration of gold in the colloidal suspension $(\mu \mathrm{g} / \mathrm{mL})$ was determined by atomic absorption spectroscopy (Avanta PM, GBC-Australia). Transmission Electron Microscopy (TEM) was used in our previous study to determine the median size of GNPc (Aldea M, 2018).

\section{Cell cultures}

Our in vitro experiment used three glioblastoma cell lines and a normal endothelial cell line. GM1 is a primary glioblastoma cell line isolated from freshly resected glioblastoma specimens that has been shown to express both stem cell markers and neural markers, as previously described by our team (12). After isolation and expansion in a serum-free medium enriched with growth factors, GM1 cells were subsequently cultured in Ham's F-12 and DMEM media used in 1:1 ratio, supplemented with $15 \%$ fetal calf serum (FCS), $100 \mathrm{U} / \mathrm{ml}$ penicillin and $100 \mu \mathrm{g} / \mathrm{ml}$ streptomycin, $2 \mathrm{mM}$ L-glutamine, $1 \%$ nonessential amino acids (NEA), $55 \mu \mathrm{M}$ betamercaptoethanol and $1 \mathrm{mM}$ sodium pyruvate. Also, two commercial glioblastoma cell lines (A172 and U251, purchased from Sigma-
Aldrich) were cultured in DMEM medium supplemented with $2 \mathrm{mM} \mathrm{L-glutamine,} 100$ $\mathrm{U} / \mathrm{ml}$ penicillin and $100 \mu \mathrm{g} / \mathrm{ml}$ streptomycin, $1 \%$ NEA, $1 \mathrm{mM}$ sodium pyruvate and $10 \%$ FCS.

Human endothelial cells (HUVEC), purchased from the European Collection of Cell Cultures (ECACC, Porton Down, Salisbury, UK) served as "normal cell model" and were cultured in RPMI medium, supplemented with $10 \%$ fetal calf serum (FCS), gentamicin $50 \mu \mathrm{g} / \mathrm{ml}$, and amphotericin $100 \mu \mathrm{g} / \mathrm{ml}$ (Biochrom AG, Berlin, Germany).

Cultures were maintained at $37{ }^{\circ} \mathrm{C}$ in a humidified atmosphere of $95 \%$ air and 5\% $\mathrm{CO} 2$. All cell culture reagents were purchased from Sigma-Aldrich Corporation (St Louis, MO, USA), unless otherwise specified.

\section{NP administration and cell internalization}

For each of the cell lines used, uncapped GNP, GNPc and MET-GNPc were administered at dose concentrations of 5,10 and $20 \mu \mathrm{g} / \mathrm{mL}$. Their internalization within cells was analyzed through dark field microscopy. Cells were cultured in Ibidi $30 \mu$ Dish of $50 \mathrm{~mm}$ and treated for $24 \mathrm{~h}$ at a concentration of $10 \mu \mathrm{g} / \mathrm{mL}$ of each nanoparticle. An inverted Zeiss Axio Observer Z1 microscope with a halogen lamp (HAL100, $100 \mathrm{~W}$, Zeiss) focused on the sample at a constant intensity through a high numerical immersion dark field condenser $(\mathrm{NA}=1.4)$ and the scattered light was collected by a LD Plan-Neofluar $\times 20$ objective (NA $=0.4$, Zeiss). Imaging acquisition was made with an AxioCam Icc digital camera and processed with the ZEN software. 


\section{Cell lines irradiation}

In order to test if MET-GNPc could be used as a radiosensitizer, cell lines were irradiated at megavoltage energies of 1.25 MV with 2, 4 and 6 Gy, by using a Cobalt Theratron100R. Control experiments were performed following exactly the same treatment protocol, but without irradiation.

\section{Cell viability after NP administration with or without irradiation}

After reaching a sub-confluence of $60-80 \%$, cells were incubated with 5,10 and $20 \mu \mathrm{g} / \mathrm{mL}$ of each nanoparticle and free drug. After $24 \mathrm{~h}$, cell viability was assessed via the MTT proliferation test, which measured the mitochondrial activity of living cells. After removing the medium and washing three times with PBS, the yellow MTT solution [3(4,5-dimethylthiazolyl-

2)-2,5diphenyltetrazolium bromide] was added and the plate was left at $37^{\circ} \mathrm{C}$ for $1 \mathrm{~h}$ to allow MTT to be metabolized. The resulting purple formazan was then re-suspended in $150 \mu \mathrm{l}$ DMSO and placed on a shaking table. The reduction of MTT to formazan takes place only when mitochondrial enzymes are active; therefore, the conversion rate can directly estimate the number of living cells. The concentration was determined by optical density at $492 \mathrm{~nm}$ by using a fluorescence microplate reader (Synergy 2, BioTek, Winooski, VT, USA).

\section{Statistical analysis}

All experiments were repeated three times and expressed as mean \pm SEM of three independent biological replicates. The comparison between groups was assessed by the one-way ANOVA followed by Bonfferoni's multiple comparison post-test. The statistical significance was set at $\mathrm{p}<0.05$ (GraphPad version 5.0 San Diego CA, USA).

\section{Results}

Physico-chemical characteristics of MET-

\section{GNPc and GNPc}

The formation of the MET-GNPc nanoparticle was validated through spectroscopic measurements. By analysing the extinction spectra of MET-GNPc and GNPc, it may be observed that the coloidal solution maintaines its stability in the presence of MET as the form of the spectra does not change.

The optical spectra of colloidal solutions in Figure 1 exhibit a dominant extinction band located at $525 \mathrm{~nm}$ for GNPc, which shows the dipolar plasmon resonance of spherical NPs. For the MET-GNPc the plasmonic band has smaller wavelengths compared with GNPc. This difference is caused by the change of the refraction index of nanoparticles as a result of MET disposal near the gold surface after its incorporation within the polymeric matrix.

In the extinction spectrum of the METGNPc, a supplementary extinction band may be observed in the ultraviolet field at $230 \mathrm{~nm}$, characteristic to MET, which proves the successful loading of GNPc with MET. MET loading efficiency and its quantity were assessed through UV-vis measurements of the initial MET used for incubation, of the supernatant collected after conjugation, of the mixture of MET-GNPc before and after centrifugation. As a supplementary control measurement, the concentration of loaded MET was measured by inducing an acid 
medium ( $\mathrm{pH} 2.5$ ), which immediately led to the release of the entire MET quantity from the GNPc, followed by a $20 \mathrm{~min}$ centrifugation at 12.000 rotations per minute. MET concentration was determined by measurements of atomic absorption. In optimal incubation conditions, we observed that MET loads on GNPc at a concentration of $80 \mu \mathrm{M}$.

Also, the complex stability was monitored in time through UV-vis-NIR spectroscopy. It has been observed that in normal 4 degrees refrigerator conditions, the colloidal METGNPc maintains its stability for a minimum of 2 months.

In our previous work, we have already demonstrated a positive zeta potential and a medium size of nearly $26 \mathrm{~nm}$ of GNPc (Aldea M, 2018). The positive zeta potential appears as a result of the protonated amino groups from the chitosan chain which characterizes both GNPc and MET-GNPc.

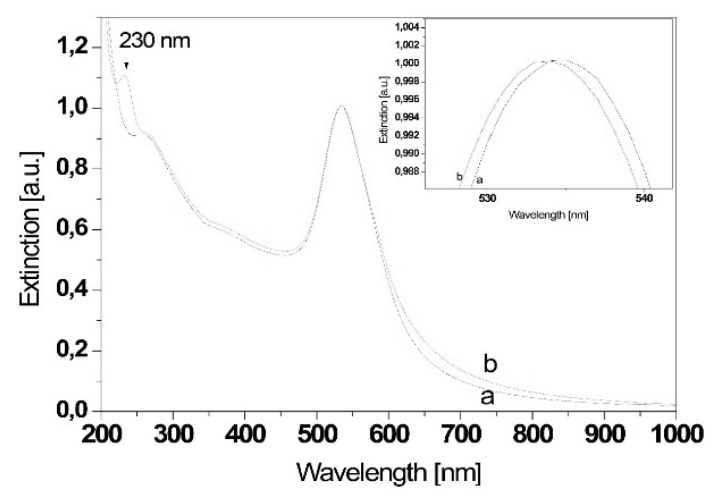

Figure 1 - UV-vis-NIR extinction spectra of GNPc (a) and MET-GNPc (b)

\section{Cellular uptake of GNPs analyzed by dark field imaging}

GNPs are easily visualized through dark field microscopy because of their surface plasmon resonances which make them able to strongly scatter the visible light. Cells were incubated at the same concentration of GNPc and MET-GNPc for 24h. The orange-red spots correspond to the light-scattering nanoparticles. As observed in Figure 2, both GNPc and MET-GNPc are highly internalized within the analyzed cell lines and they are located mostly throughout all the cytoplasm.

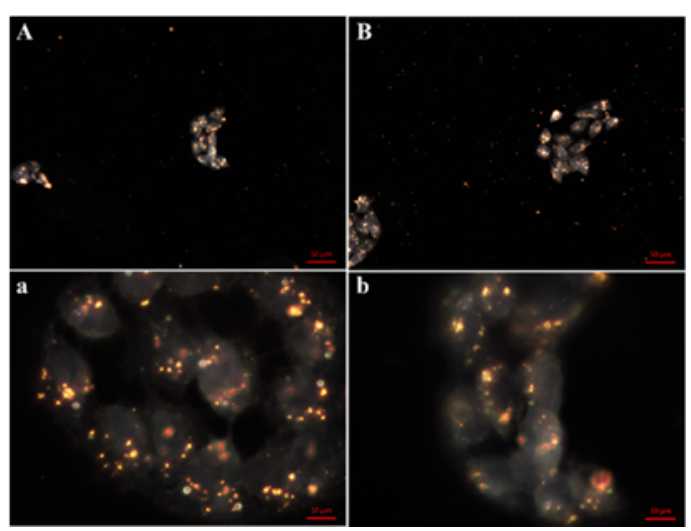

Figure 2 - Dark field microscopy images of GM1 cells incubated with GNPc and MET-GNPc for $24 \mathrm{~h}$. (A), (a) GNPc; (B), (b) MET-GNPc

\section{GNPc and MET-GNPc impacts the viability of glioblastoma cell lines}

The tested cell lines included both glioblastoma stem-like cells (GM1) and commercial non-stem glioblastoma cells (A172 and U251) in order to investigate if the stem cell character confers any resistance or sensitivity to MET-GNPc. Also, an endothelial cell lines was used as a normal cell line. 
The MTT viability test showed that the most sensitive cell lines were GM1 and U251, which were impacted by the 10 and $20 \mu \mathrm{g} / \mathrm{mL}$ concentrations of both GNPc and MET-GNPc $(\mathrm{p}<0.001)$ (Figure 3). Although MET-GNPc significantly affects cell proliferation when compared to control and uncapped GNPc, there is no difference when compared to the chitosan-capped GNPc $(p>0.05)$. Therefore, it seems that the tumor cell viability is affected mainly by the chitosan component of the nanoparticles and that the benefit of MET loading is only minor and does not lead to an additional benefit in terms of cell viability.

MET-GNPc and GNPc slightly affect the endothelial cell line, especially when used at the $20 \mu \mathrm{g} / \mathrm{mL}$ concentration $(\mathrm{p}<0.05)$.
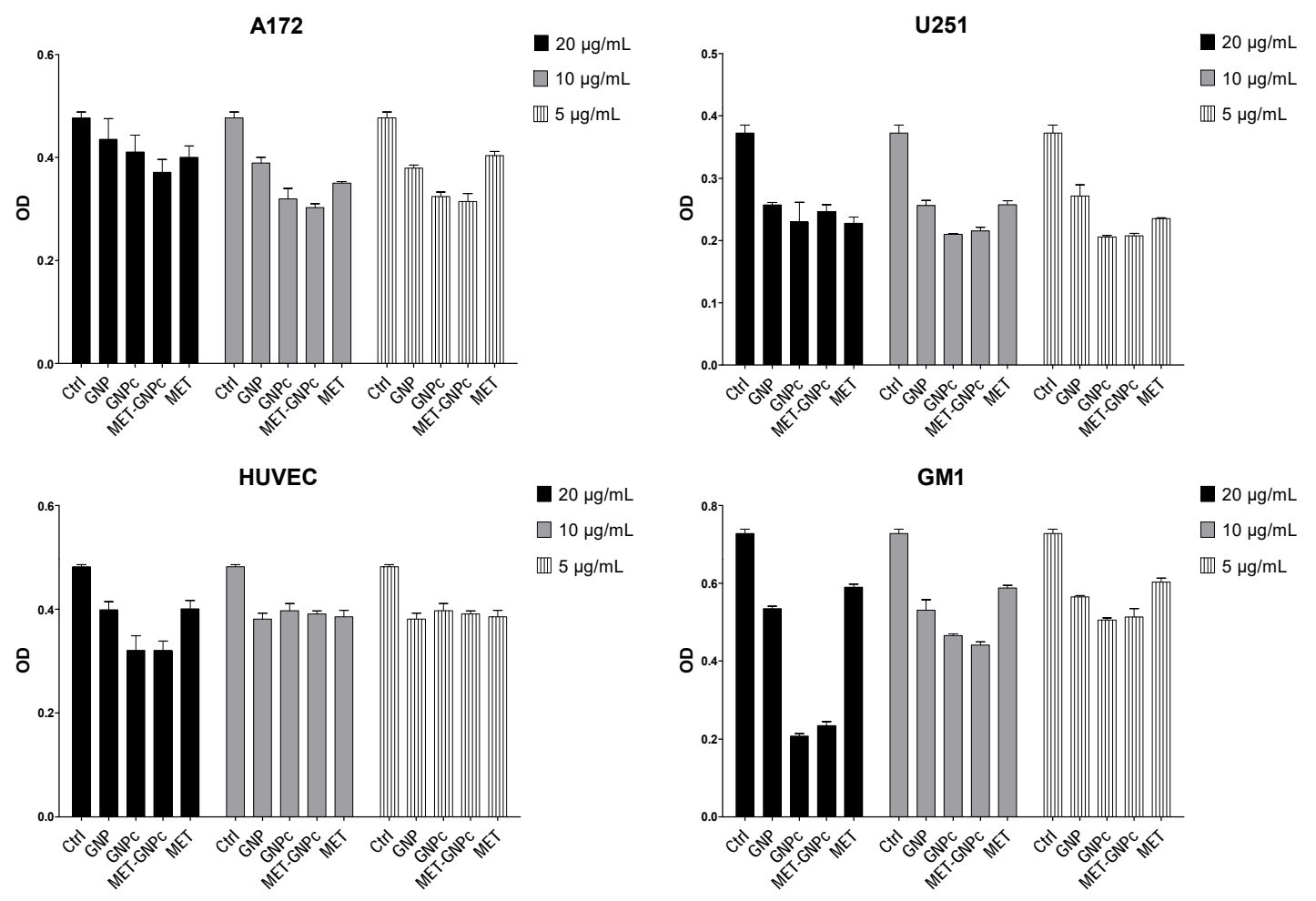

Figure 3 - MTT viability assay after 24h incubation with treatments (control, GNP, GNPc, MET-GNPc, MET). Increasing doses of each treatment $(5 \mu \mathrm{g} / \mathrm{mL}, 10 \mu \mathrm{g} / \mathrm{mL}$ and $20 \mu \mathrm{g} / \mathrm{mL})$ showed that cell viability was affected in a dose dependent manner (non-significant for the $5 \mu \mathrm{g} / \mathrm{mL}$ dose). Cell viability is mostly affected by the GNPc and MET-GNPc used at the $20 \mu \mathrm{g} / \mathrm{mL}$ concentration for each glioblastoma cell line $(\mathrm{p}<0.001)$. HUVEC cells were also affected by NP treatments, but only when treated with the $20 \mu \mathrm{g} / \mathrm{mL}$ concentration $(\mathrm{p}<0.05)$ 
A172

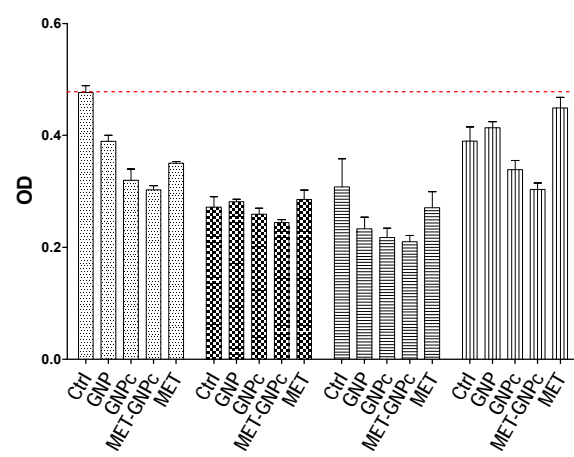

HUVEC

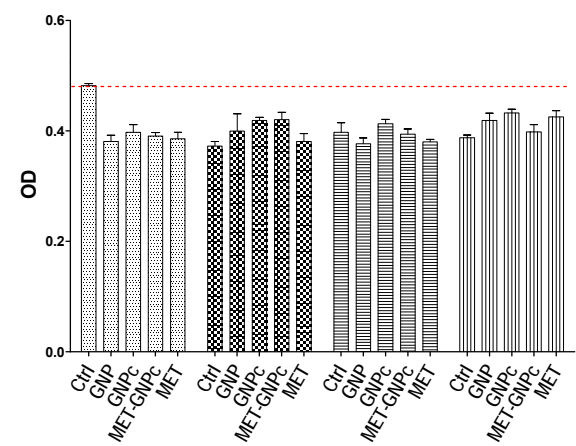

U251

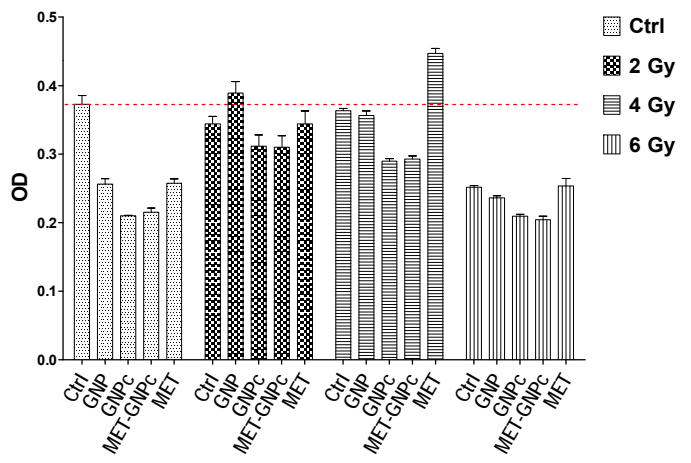

GM1

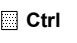

$2 \mathrm{~Gy}$

自 4 Gy

而 6 Gy

Figure 4 - Irradiated versus non-irradiated cells. Glioblastoma cell lines are affected by irradiation with a slight tendency of an enhanced response when combined to GNPc and MET-GNPc treatment $(p<0.05)$. The addition of nanoparticles does not increase the toxicity of irradiation upon HUVEC, which are resistant to radiotherapy

$(\mathrm{p}>0.05)$

\section{Radiotherapy shows no additional benefit when combined with GNPc or MET-GNPc}

We investigated if such GNPc with or without MET could sensitize cells to irradiation. All tested NPs were used at a 10 $\mu \mathrm{g} / \mathrm{mL}$ concentration and irradiated with increasing doses of 2, 4 and 6 Gy. HUVEC normal cell lines proved the highest resistance to irradiation and the combination between irradiation and nanoparticles did not impact their viability $(\mathrm{p}>0.05)$.
The response of the tumoral cell lines was different mainly depending on their proliferation index, but also on their intrinsic radioresistance. The A172 cell line was impacted by the 2 Gy and 4 Gy irradiation fractions, with a slight benefit when GNPc was combined with 4 Gy irradiation, but intriguingly, the 6 Gy dose was no different than the unirradiated control. The U251 cell line, which has a lower proliferation index, proved to be resistant at small doses of irradiation, but the combination of $4 \mathrm{~Gy}$ 
irradiation and GNPc with/without MET was more toxic and decreased cell viability compared to each treatment alone $(\mathrm{p}<0.05)$. However, this additional benefit was not observed when the 6 Gy dose was used, despite the fact that this dose impacted cell proliferation.

The stem-like cell GM1 proved the best response when radiotherapy at higher doses was combined with nanoparticles as shown by their decreased viability when 4 and 6 Gy doses of irradiation were combined with METGNPc or GNPc (Figure 4).

\section{Discussions}

MET has shown an excellent antiglioblastoma activity in numerous in vitro studies, by inhibiting the self-renewal capacity of glioblastoma stem cells, expression of stem cell markers, as well as their invasion and migration properties. However, the antiproliferative effects of MET were proven mainly when used at high drug concentrations, as many in vitro experiments used millimolar metformin concentrations (Song et al., 2018). From a translational point of view, such concentrations are not attained in the clinics by the maximal anti-diabetic dose normally used. Therefore, in this study, our aim was to test if an enhanced delivery and internalization of MET via nanoparticles, could overcome the limitation of small drug concentrations.

Nanotechnology holds an excellent potential of providing a preferential drug administration within the tumor, with an enhanced internalization and efficient drug delivery at the targeted site (Suri, Fenniri, \&
Singh, 2007). Our team previously synthetized chitosan-capped GNP and proved that such nanoparticles are highly internalized by glioblastoma-stem like cells and by normal osteoblasts cells. Intriguingly, GNPc proved a selective anti-proliferative effect for glioblastoma cells, as compared with uncapped GNP which had no anti-tumor effect. Despite an important intracellular accumulation within osteoblasts, GNPc showed no toxicity on the normal cell line. The increased intratumoral internalization of GNPc and their selective cytotoxicity on cancer cells have suggested that such NPs could be a promising vector for anti-cancer drugs (Aldea M, 2018).

Therefore, our team further synthetized GNPc and managed to functionalize them with small micromolar concentration of MET, in order to test if their enhanced delivery would lead to a therapeutic drug efficiency within the tumor cells. The synthesis of MET nanoparticles was an easy, reproducible method and resulted in the development of a stable compound, with physico-chemical characteristics similar to GNPc. However, although both GNPc and MET-GNPc had an important intracellular accumulation and proved to impact the survival of glioblastoma cells, there were no statistically significant differences between GNPc and MET-GNPc, suggesting that MET does not bring an additional benefit when used in small micromolar drug concentrations.

Considering the important anti-cancer effects proved by MET used in millimolar concentrations, further research must be made in order to find a suitable delivery method. 
Kumar et al. synthetized a similar gold nanoparticle for the targeted delivery of metformin by capping GNPs with hyaluronic acid. The enhanced MET delivery was able to improve the anti-cancer activity of the METGNP complex compared to free MET in the treatment of liver cancer cells (Kumar, Raja, Sundar, Gover Antoniraj, \& Ruckmani, 2015). An alternative way would be the development of NPs that would permit higher MET binding, by paying attention also to the fact that the increasing concentration of NPs would increase the quantity of excipients within the brain. Possible biodegradable NPs are more desirable for this purpose. Also, another strategy to increase drug concentrations would be the intratumoral administration of MET or within the tumoral cavity after surgical resection (Aldea et al., 2016).

\section{Conclusion}

Herein, we have developed a novel GNP loaded with MET, by using a biocompatible and biodegradable polymer, chitosan, as a reducing agent. This formulation exhibited high cell internalization due to the use of GNPc and had an increased anti-glioblastoma activity compared to free MET used in small micromolar concentrations. However, METGNPc does not add a significant benefit when compared to GNPc possible due to the small MET concentrations used for binding. Therefore, an increased internalization of MET-GNPc loaded with micromolar concentrations of MET does not prove the same anti-cancer effectiveness of millimolar concentrations of free MET. Improved delivery methods with an increased MET loading should be tested.

\section{Acknowledgements}

This research was financially supported by an EUFISCDI National Grant - PNII-RU-TE2014-4-0225 (ENERGY), Competition for Young Teams, Program for Human Resources. M.A. was also financed by a research grant for $\mathrm{PhD}$ Fellows (contract number 7690/2/15.04.2016) offered by the University of Medicine and Pharmacy (ClujNapoca).

\section{Correspondence}

Prof. Ioan Stefan Florian, MD PhD

Victor Babes str, no 43, 400012, Cluj-Napoca,

Romania

E-mail: stefanfloriannch@gmail.com

Mihaela Aldea, $M D$

Republicii str, no 34-36, 400012, Cluj-Napoca,

Romania

Tel: +40741007967

E-mail:mihaela.aldea1@gmail.com

\section{References}

1.Aldea, M., Craciun, L., Tomuleasa, C., BerindanNeagoe, I., Kacso, G., Florian, I. S., \& Crivii, C. Repositioning metformin in cancer: genetics, drug targets, and new ways of delivery. Tumour Biology, 35(6), 5101-5110, 2014

2.Aldea, M., Florian, I. A., Kacso, G., Craciun, L., Boca, S., Soritau, O., \& Florian, I. S. Nanoparticles for Targeting Intratumoral Hypoxia: Exploiting a Potential Weakness of Glioblastoma. Pharm Res, 33(9), 2059-2077, 2016

3.Aldea M, P. M., Soritau O, Florian IS, Florea A, NagySimon T, Pileczki V, Brie I, Maniu D, Kacso G. Chitosancapped gold nanoparticles impair radioresistant glioblastoma stem-like cells. J BUON, 23(3), 800-813, 2018 4.Aldea, M. D., Petrushev, B., Soritau, O., Tomuleasa, C. I., Berindan-Neagoe, I., Filip, A. G., Kacso, G. Metformin 
plus sorafenib highly impacts temozolomide resistant glioblastoma stem-like cells. J BUON, 19(2), 502-511, 2014

5.Carmignani, M., Volpe, A. R., Aldea, M., Soritau, O., Irimie, A., Florian, I. S., Valle, G. Glioblastoma stem cells: a new target for metformin and arsenic trioxide. Journal of Biological Regulators and Homeostatic Agents, 28(1), $1-15,2014$

6.Kordes, S., Pollak, M. N., Zwinderman, A. H., Mathot, R. A., Weterman, M. J., Beeker, A., Wilmink, J. W. Metformin in patients with advanced pancreatic cancer: a double-blind, randomised, placebo-controlled phase 2 trial. Lancet Oncol, 16(7), 839-847, 2015

7.Kumar, C. S., Raja, M. D., Sundar, D. S., Gover Antoniraj, M., \& Ruckmani, K. Hyaluronic acid cofunctionalized gold nanoparticle complex for the targeted delivery of metformin in the treatment of liver cancer (HepG2 cells). Carbohydr Polym, 128, 63-74, 2015

8.Nenu, I., Popescu, T., Aldea, M. D., Craciun, L., Olteanu, D., Tatomir, C., Filip, A. G. Metformin associated with photodynamic therapy--a novel oncological direction. Journal of Photochemistry and Photobiology. B: Biology, 138, 80-91, 2014

9.Potara, M., Maniu, D., \& Astilean, S. The synthesis of biocompatible and SERS-active gold nanoparticles using chitosan. Nanotechnology, 20(31), 315602, 2009

10.Reni, M., Dugnani, E., Cereda, S., Belli, C., Balzano, G., Nicoletti, R., . . Piemonti, L. (Ir)relevance of Metformin Treatment in Patients with Metastatic Pancreatic Cancer:
An Open-Label, Randomized Phase II Trial. Clinical Cancer Research, 22(5), 1076-1085. 2016

11.Sayed, R., Saad, A. S., El Wakeel, L., Elkholy, E., \& Badary, O. Metformin Addition to Chemotherapy in Stage IV Non-Small Cell Lung Cancer: an Open Label Randomized Controlled Study. Asian Pacific Journal of Cancer Prevention, 16(15), 6621-6626, 2015

12.Sesen, J., Dahan, P., Scotland, S. J., Saland, E., Dang, V. T., Lemarie, A., Skuli, N. Metformin inhibits growth of human glioblastoma cells and enhances therapeutic response. PLoS One, 10(4), e0123721, 2015

13.Song, Y., Chen, Y., Li, Y., Lyu, X., Cui, J., Cheng, Y., Zhao, G. (2018). Metformin inhibits TGF-betal-induced epithelial-to-mesenchymal transition-like process and stem-like properties in GBM via AKT/mTOR/ZEB1 pathway. Oncotarget, 9(6), 7023-7035, 2018

14.Soritau, O., Tomuleasa, C., Aldea, M., Petrushev, B., Susman, S., Gheban, D., Florian, I. S. Metformin plus temozolomide-based chemotherapy as adjuvant treatment for WHO grade III and IV malignant gliomas. J BUON, 16(2), 282-289, 2011

15.Suri, S. S., Fenniri, H., \& Singh, B. Nanotechnologybased drug delivery systems. Journal of Occupational Medicine and Toxicology, 2, 16, 2007

16.Turkevich J, C. S. P., Hillier J. A study of the nucleation and growth processes in the synthesis of colloidal gold. Discuss. Faraday Soc., 11, 55-75, 1951 